Document downloaded from:

http://hdl.handle.net/10251/37707

This paper must be cited as:

Rodriguez Martinez, ED.; Bernal, SA.; Provis, JL.; Paya Bernabeu, JJ.; Monzó Balbuena, JM.; Borrachero Rosado, MV. (2013). Effect of nanosilica-based activators on the performance of an alkali-activated fly ash. Cement and Concrete Composites. 35(1):1-11. doi:10.1016/j.cemconcomp.2012.08.025.

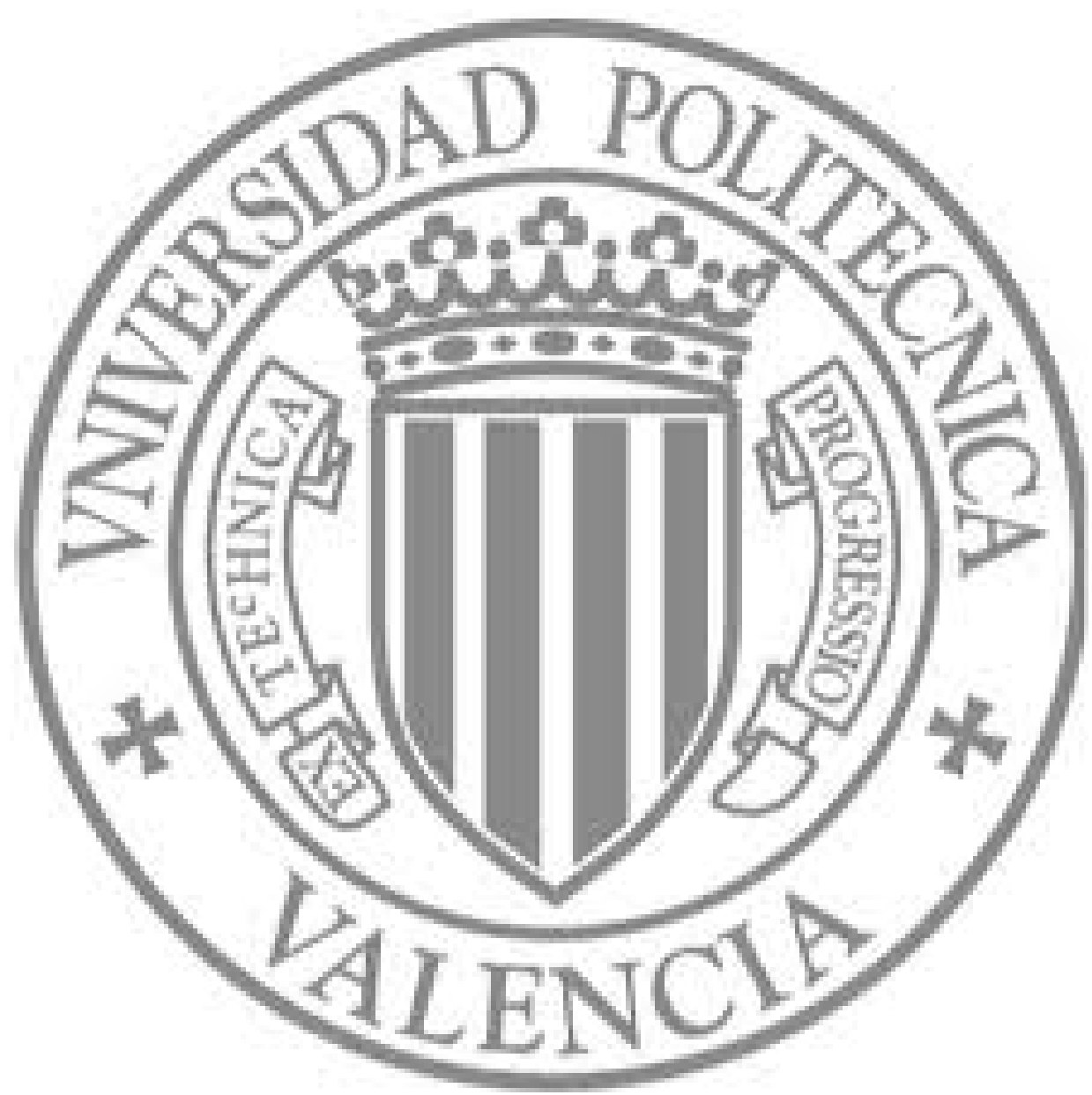

The final publication is available at

http://dx.doi.org/10.1016/j.cemconcomp.2012.08.025

Copyright Elsevier 


\section{Effect of nanosilica-based activators on the performance of an alkali-activated fly ash} binder

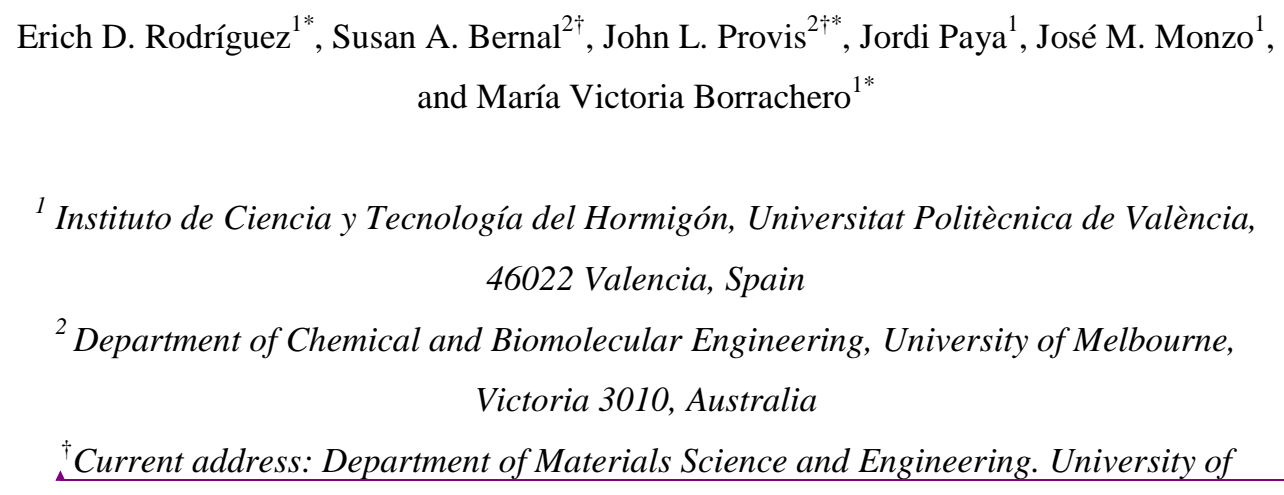

${ }^{2}$ Department of Chemical and Biomolecular Engineering, University of Melbourne, Victoria 3010, Australia

\section{${ }_{4}^{\dagger}$ Current address: Department of Materials Science and Engineering. University of} Sheffield, Sheffield, United Kingdom.

* To whom correspondence should be addressed. Email: errodnar@disca.upv.es, erichdavidrodriguez@gmail.com (EDR); j.provis@sheffield.ac.uk (JLP) phone: +34-963 877007 (75648), fax: +34-963 877569

\section{Abstract}

This paper assesses the effect of the use of an alternative activator based on nanosilica/MOH $\left(\mathrm{M}=\mathrm{K}^{+}\right.$or $\left.\mathrm{Na}^{+}\right)$blended solutions on the performance of alkali-activated fly ash binders. Binders produced with commercial silicate activators display a greater degree of reaction, associated with increased contents of geopolymer gel; however, mortars produced with the alternative nanosilica-based activators exhibited lower water demand and reduced permeability, independent of the alkali cation used. Na-based activators promote higher compressive strength compared with K-based activators, along with a refined pore structure, although K-activated samples exhibit reduced water demand. Zeolite type products are the major crystalline phases formed within these binders. A wider range of zeolites is formed when using commercial silicate solutions compared with the alternative activators. These results suggest that there are variations in the availability of Si in the system, and consequently in the alkalinity, depending on the silicate source in the activator, which is important in determining the nanostructure of the geopolymer gel.

Keywords: Alkali-activated binders, soluble silicate solutions, nanosilica, X-ray diffraction, scanning electron microscopy 


\section{Introduction}

Interest in the development of alternative building materials such as alkali-activated binders has been promoted by the growth of the building industry, the increased performance requirements placed upon materials, and the higher sustainability criteria applied in construction. Alkali-activated binders represent an attractive alternative for the partial or complete substitution of Portland cement in the production of mortars and concretes, offering comparable performance and cost [1] while reducing greenhouse gas emissions [2]. Specifically, the alkali-activation of low calcium fly ashes (FA) has been extensively assessed over the past decades because these binders exhibit mechanical performance comparable to that reported for Portland cement, and because FA is an industrial by-product available worldwide. FA is produced in high amounts, especially in countries such as India and China, where an increased demand for cement is expected in the coming years. Despite the promising properties of these binders, and their ongoing commercialization, there are technological challenges associated with the variability of the raw materials from different sources, and the low sustainability of the current alkaliactivators used [3].

In the activation of aluminosilicate precursors such as FA, the nature of the activator solution plays a key role in determining structural and mechanical performance. The most relevant characteristics related to the alkali activator are: the type of alkaline salt (usually silicate or hydroxide) [4-6]; the method of addition of the alkaline component (as a solution or in solid-state) [7-9], and the dosage of the alkali component, usually expressed as molar ratios considering the overall composition of the raw material. Additionally, it has been reported [4, 10-11] that the alkali cation supplied by the alkaline solution influences the first stages of binder formation, and consequently the mechanical performance of the final products. The alkali-activators conventionally used are sodium or potassium hydroxides, and/or sodium or potassium silicates [12]. Activation with Kcontaining solutions often leads to increased compressive strength development when compared with Na-containing solutions, where the size and charge density of the alkali cation play an important role in controlling the rate and extent of condensation during the polycondensation or crystallization process [13]. However, these effects are also dependent on the chemical and physical nature of the solid precursor used [5]. 
The embodied energy associated with the preparation of an alkali-activated binder is often estimated based on the contributions of the precursor and the alkaline activator. Some studies have analyzed the real energy consumed in fly ash based geopolymer production

72 [14-15], identifying that the major contribution is associated with the type and concentration of the alkaline activator, and is between $0.5 \mathrm{MJ} / \mathrm{t}$ and $3.4 \mathrm{MJ} / \mathrm{t}$. This is mainly related to the complex chemical processes required to manufacture these substances. For instance, the production of sodium silicate involves the calcination of sodium carbonate $\left(\mathrm{Na}_{2} \mathrm{CO}_{3}\right)$ and quartz sand $\left(\mathrm{SiO}_{2}\right)$ at temperatures between $1400-1500^{\circ} \mathrm{C}$, producing large amounts of $\mathrm{CO}_{2}$ as a secondary product [16-18]. This substantially increases the embodied energy of silicate-activated binders, reducing sustainability. However, sodium silicate $\left(\mathrm{Na}_{2} \mathrm{O} \cdot r \mathrm{SiO}_{2}\right.$, sometimes referred to as 'waterglass') is the activator which generally provides the highest compressive strength development at early ages of curing, and exhibits some technological advantages compared with other activators such as $\mathrm{NaOH}$.

This then provides motivation for the examination of the current activators used in geopolymerization processes in terms of their sustainability, and the assessment of alternatives that can contribute to reducing the embodied energy of these binders. Some studies assessing alternative activators based on modified silica fume (MSF) have been conducted [19-21]. Likewise, agro-industrial wastes, as well as other silica sources, have been studied as alternative alkali-activators in order to obtain a more environmentally

90 friendly alkali-activated binder with lower cost [22-27]. These results reveal that this 91 alternative activator promotes similar or even better mechanical performance when compared with conventional activators.

Based on this background, the aim of this paper is to study alkali-activated low calcium fly ash binders, activated by chemically modified nanosilica. The effect of the alkali cation

$96 \mathrm{Na}^{+}$and $\left.\mathrm{K}^{+}\right)$on the structure of the binders is studied by X-ray diffraction (XRD), thermogravimetry and electron scanning microscopy (SEM/EDS). Compressive strength testing and mercury intrusion porosimetry (MIP) are conducted on mortar samples based on the binders produced, in order to generate a better understanding of the effect of the type of activator used, the gel structure formed, and the mechanical strength development of the materials. 
103

104

105

106

107

108

109

110

111

112

113

114

115

116

117

118

119

120

121

122

123

124

125

126

127

128

129

130 As alkali-activators, four alkaline solutions derived from hydroxide solutions and soluble

131 silica sources were used. A commercial sodium silicate (SS) from Merck and a potassium

132 silicate (SK) from IQE were used as reference soluble silica sources (Table 2). Two

133 additional soluble silicates based on blends of a nanosilica suspension from H.S. Starck

134 (L300, specific surface $300 \mathrm{~m}^{2} / \mathrm{g}$; Table 2) were also assessed. Alkali-activators were

135 prepared by the dissolution of analytical sodium hydroxide (99 wt\%) or potassium

\subsection{Materials}

The binders studied here were synthesized using a fly ash (FA) from Teruel Power Station in Andorra, Spain, with a specific gravity of $2520 \mathrm{~kg} / \mathrm{m}^{3}$ and a chemical composition as shown in Table 1. The FA was mechanically treated in a high impact mill (Mill2 Gabbrielli) to increase its reactivity. The particle size range determined by laser granulometry was $0.2-80 \mu \mathrm{m}$, with a mean particle size of $15 \mu \mathrm{m}$, and a specific surface of $1130 \mathrm{~m}^{2} / \mathrm{kg}$.

Table 1. Chemical composition of the fly ash from X-ray fluorescence analysis. LOI is loss on ignition at $950{ }^{\circ} \mathrm{C}$

The X-ray diffraction pattern of the FA (Figure 1) shows that the major crystalline phases present are quartz $\left(\mathrm{SiO}_{2}\right.$; Powder Diffraction File (PDF) card \# 00-046-1045), mullite $\left(\mathrm{Al}_{6} \mathrm{Si}_{2} \mathrm{O}_{13}\right.$; PDF\# 00-015-0776), and Fe-rich phases such as hematite $\left(\mathrm{Fe}_{2} \mathrm{O}_{3}\right.$; PDF\# 00033-0664), iron silicate $\left(\mathrm{Fe}_{7} \mathrm{SiO}_{10}\right.$; $\mathrm{PDF} \#$ 00-022-1118), and some ferrite spinels (magnetite - $\mathrm{Fe}_{3} \mathrm{O}_{4}$; $\mathrm{PDF} \# 00-019-0629$, with and without substituent elements such as $\mathrm{Mg}$ and $\mathrm{Al}$ on both $\mathrm{Fe}^{2+}$ and $\mathrm{Fe}^{3+}$ sites). The presence of these phases is coherent with the high content of iron in the fly ash and has been previously observed in other fly ashes [28-30]. It is important to note that the ferrite spinels in the FA play an important role in the potential hosting of heavy metals, as $\mathrm{Fe}^{3+}$ sites can be substituted by trivalent cations such as $\mathrm{Cr}^{3+}[31]$.

Figure 1. Cu- $\mathrm{K}_{\alpha}$ diffractogram of the fly ash after mechanical treatment 
hydroxide (85 wt\%) pellets along with the silica source to obtain a molar oxide ratio

$137 \mathrm{SiO}_{2} / \mathrm{M}_{2} \mathrm{O}$ equal to 1.16 , where $M$ corresponds to $\mathrm{Na}^{+}$or $\mathrm{K}^{+}$.

Table 2. Chemical composition of reference silicate activators and nanosilica used to prepare nanosilica/MOH activators; data provided by the suppliers

\subsection{Sample synthesis and test procedure}

\subsubsection{Pastes}

Alkali-activator with a molar oxide ratio $\mathrm{SiO}_{2} / \mathrm{M}_{2} \mathrm{O}$ of 1.16 was incorporated at $12.0 \mathrm{wt} \%$ $\mathrm{Na}_{2} \mathrm{O}$ or $18.2 \mathrm{wt} \% \mathrm{~K}_{2} \mathrm{O}$ by mass of fly ash, providing equivalent alkali concentrations on a molar basis for the samples prepared with different alkalis. All specimens were produced by mechanical mixing for 4 minutes, including different contents of water in order to obtain similar workability (Table 3). It is important to note that the water/binder values consider the liquids and solids contributed by both the activator and the precursor (i.e. binder $=$ fly ash + anhydrous activator) .

Table 3. Mix description of silicate-activated fly ash binders

For the structural study of hardened pastes, the specimens were cast in cylindrical molds and cured at a relative humidity (RH) of $90 \%$ and a temperature of $65^{\circ} \mathrm{C}$, for $48 \mathrm{~h}$. Afterwards, samples were kept in a high humidity atmosphere ( $\mathrm{RH} \geq 90 \%)$ at room temperature $\left(\sim 25^{\circ} \mathrm{C}\right)$. The reaction process was stopped at specified times by crushing the samples and submerging them in acetone for 15 min, filtering and drying. In order to prevent the carbonation of the powders thus obtained, these were stored in sealed containers, and then analyzed:

- X-ray diffraction (XRD) was carried out using a Bruker D8 Advance instrument with $\mathrm{Cu} \mathrm{K} \alpha$ radiation and a nickel filter. The tests were conducted with a step size of $0.020^{\circ}$, for a $2 \theta$ range of $3^{\circ}$ to $65^{\circ}$.

- A thermobalance TGA-850 (Mettler Toledo) was used to analyze crushed samples at a heating rate of $10^{\circ} \mathrm{C} / \mathrm{min}$ up to $1000^{\circ} \mathrm{C}$, with an alumina crucible in an dry air atmosphere. 
- Scanning electron microscopy (SEM) was conducted using a JEOL JSM6300 microscope with a tungsten filament electron source, and $20 \mathrm{kV}$ accelerating voltage. The samples were evaluated in high vacuum mode. Attached to this instrument a LinkIsis (Oxford Instruments) X-ray spectrometer system (energy dispersive spectroscopy (EDS)) was used to determine the chemical compositions of the phases identified.

\subsubsection{Mortars}

Mortars were produced using a siliceous sand with a fineness modulus of 4.1 and specific weight of $2680 \mathrm{~kg} / \mathrm{m}^{3}$, in accordance with the standard procedure UNE-EN 196-12005. All samples were formulated with a standard fly ash:sand ratio of $1: 3$, cast in prismatic moulds of $40 \times 40 \times 160 \mathrm{~mm}$, compacted and mechanically vibrated for three minutes. Curing was conducted in similar conditions as previously described for pastes; however, after the period of curing at high temperature, mortars were stored in sealed containers at $\mathrm{RH} \sim 90 \%$ and room temperature until testing. Compressive strength was determined after 2, 28 and 60 days following the standard testing protocol UNE-EN-1015-11. Additionally, mercury intrusion porosimetry (MIP) was conducted after 28 days using an AutoPore IV 9500 (Micromeritics) instrument, with applied intrusion pressures between $13.8 \mathrm{kPa}$ and 227.4 MPa.

\section{Results and discussion}

\subsection{Water demand}

From visual inspection, it was possible to identify that mixes produced with reference Kbased activators (commercial potassium silicate solution) exhibited increased workability when compared with pastes produced with the reference Na-based activator (commercial sodium silicate solution), which allowed a significant reduction of the total water included in these binders while achieving a similar slump. Similar behavior has been reported in the literature [5] for pastes prepared with K-based activators, which exhibit increased slump compared to those prepared with Na-based activators. Additionally, the lower silica content of the K-containing solutions will also have an effect in the fresh mixes, because an increased content of silica in the alkali activator (higher Ms) causes reduced workability of the fresh mixture, related to the higher viscosity identified in both $\mathrm{Na}$ and $\mathrm{K}$ silicate solutions at increased silica concentrations [12]. 
204 The water demand of the binders prepared with the nanosilica-based activator is lower than that of the pastes based on the reference silicate activators. Pastes including the nanosilica-solution presented better workability than those prepared with commercial silicate activator, independent of the alkali cation included in the solution, at an equivalent $\mathrm{M}_{2} \mathrm{O} / \mathrm{SiO}_{2}$ molar ratio. This is a consequence of the structural differences between the nanosilica activator and the commercial silicate solutions. The low water demand of the L300-K paste is particularly notable, where a water content less than half of that of the SNa sample is sufficient to provide good workability.

It is expected that in the commercial silicate solutions there will be a wide range of dissolved silicate species, and among these, increased oligomer sizes affect the kinetics of the exchange of silicate units during geopolymerization [32], contributing to an increment in the viscosity of the solution, and consequently to the reduced workability of the activated pastes. Conversely, in the nanosilica-derived activator, the rate of release of soluble silicates is affected by the degree of dissolution of the particles in the hydroxide solutions during the preparation of the activator. Considering that the time of preparation of the activator is not longer than 5 hours before use (sufficient time for the solution to cool to room temperature after the exothermic dissolution), not all of the nanosilica will be completely dissolved in the hydroxide solution, and the oligomers formed in these silicates might be lower in size compared to those in commercial silicates. This would then decrease the viscosity of the nanosilica-derived activators, and consequently contribute to the higher workability of the pastes produced with this activator, with reduced water demand.

Improved workability associated with lower water demand in these binders is desirable from a durability point of view, because a reduced degree of permeability of aggressive agents through the hardened binders might be able to be achieved using these alternative activators to enable the use of lower water/binder ratios. Detailed analysis of the pore structure of these systems is presented later in this paper. 


\subsection{Compressive strength}

All of the binders assessed show compressive strengths between 84 and 88 MPa after 2 days of curing at $65^{\circ} \mathrm{C}$ (Figure 2). These mortar compressive strength values enable the classification of these materials as high performance binders, considering that conventional Portland cement concretes with compressive strengths up to $60 \mathrm{MPa}$ are classified as high performance, and to achieve these strengths generally requires the addition of chemical and/or mineral admixtures [33].

Figure 2. Compressive strength of alkali-activated fly ash mortars, as a function of the nature of the activator. Error bars indicate one standard deviation either side of the mean

As a consequence of the wide range of factors affecting the mechanical strengths of fly ash geopolymer binders, and the physical and chemical differences between fly ash and activator sources used by different research teams, it is difficult to make direct comparisons between the strengths reported by different authors. However, considering the relationship between the molar composition of the precursor and the mechanical strength proposed by Duxson and Provis [34], this ash will be expected to give good strength based on its chemical composition, which is coherent with the results reported here.

Mortars produced with Na-based activators present higher compressive strength than those with K-based activators. In both cases, slightly higher compressive strengths are obtained when using commercial silicates, especially at early ages. This effect is more notable in samples activated with the $\mathrm{L} 300-\mathrm{K}$ solution, which present compressive strengths up to 10MPa lower than the reference specimens (S-K). However, specimens prepared with the modified nanosilica activators present a clear linear trend in the strength development, so that at longer periods of curing (60 days) the compressive strengths of these mortars are comparable to those reported for the reference samples (S-Na and S-K).

These results are coherent with the mechanisms of activation which are known to take place when different alkali cations are incorporated in the binder. Xu et al. [35] observed that activation with $\mathrm{NaOH}$ promotes a higher degree of dissolution of aluminosilicate solids when compared with $\mathrm{KOH}$. This is attributed to the higher capacity of $\mathrm{NaOH}$ to 
favor the release of silicate and aluminate monomers [36-37], while $\mathrm{K}$ promotes

272 condensation reactions to a greater extent, leading to the presence of more polysilicate species [13].

In alkali activation of metakaolin, the rate of reaction in alkaline K-enriched environments is sufficient to promote a high extent of dissolution while favoring condensation of reaction products at early ages [37]. This is one of the main reasons why, in metakaolinbased geopolymers, increased compressive strengths are obtained using $\mathrm{K}$ silicate activators compared with systems where Na silicate is the alkali source. Considering that the rate of dissolution of fly ash in an alkaline environment is lower than that of metakaolin [34], it might be expected that there would be a retardation of reaction kinetics when using K-based activators. This is consistent with the lower compressive strength development exhibited by S-K and L300-K samples. The slightly lower mechanical strength values at early ages of curing reported for mortars prepared with the modified nanosilica can be attributed to the lower dissolved silica content of the nanosilica/MOH solutions compared with commercial silicate solutions, where the presence of remnant, partially dissolved silica particles slows down the availability of $\mathrm{SiO}_{2}$ in the system.

\subsection{Pore size distribution}

The MIP technique has some limitations related to measuring pore parameters in cementitious materials due to the presence of different sizes and shapes of pores, where deviations from cylindrical pore shapes will increase the measured volume of the very small pores [38]. However, it is still a valuable technique providing information about the threshold diameters and intrudable pore space, giving a better understanding of the effects of the different activators on the connectivity and capacity of the pore structure in the geopolymers assessed.

In general, K-geopolymers present lower total porosity than Na-geopolymer mortars, as seen by the lower cumulative volume intruded (Figure 3). Also, the lowest porosity is exhibited by samples prepared with the chemically modified nanosilica activator. Mortars produced with the K-nanosilica activator (L300-K) reported a total porosity of $6.32 \%$, followed by those specimens produced with the Na-nanosilica activator (L300-Na) with a total porosity of $9.75 \%$. These results are consistent with the reduced water demand of the 
chemically modified nanosilica-activated geopolymers, highlighting the benefit of using this alternative activator.

Figure 3. Cumulative volume of mercury intruded as a function of pore diameter for SNa, L300-Na and L300-K mortars after 28 days of curing

The pore size distributions of the mortars assessed are presented in Figure 4, as calculated from the applied pressure via the Washburn equation [39], assuming a contact angle of 130.0 degrees. In general, only slight differences are identified between the samples in terms of the volumes of pores with diameters higher than $\sim 10 \mu \mathrm{m}$ in samples prepared with different alkali cations, despite the reduced water demand exhibited by K-activated geopolymers compared with the Na-activated geopolymer mortars.

Figure 4. Pore size distributions obtained from mercury intrusion data for silicateactivated fly ash mortars with 28 days of curing

A remarkable effect of the alkali cation on the pore size distribution is identified in the region of diameters smaller than $1 \mu \mathrm{m}$, where an increased pore volume is reported for L300-Na mortars compared with L300-K mortars. In this region two types of porosity can be identified: macropores (50-200 nm) and mesopores (3.6-50nm). Mesopores are present into the aluminosilicate gel network due to short-range ordering which is characteristic of an amorphous material. Macropores are formed during the early stages of geopolymerization, and may transform to mesopores with the progress of the polycondensation of hydrated gels in the binders, as a consequence of the filling of the larger pores with the new reaction products, particularly given the relatively high Ca content of the fly ash used here. On the other hand, pores larger than 200nm in the geopolymer pastes are likely to be associated with the interfacial spaces between partiallyreacted or unreacted fly ash particles and the geopolymer gel [38, 40]. It is important to note that complete dissolution and reaction of precursors have never been observed in fly ash geopolymer binders, in particular when the solid precursor contains unreactive crystalline phases as is the case for the precursor used in the present study (Figure 1).

These results indicate that, although L300-Na mortars have higher water content and thus report a higher total porosity than L300-K mortars, a higher extent of polycondensation of 
the geopolymer gel is taking place in the presence of $\mathrm{Na}$. This leads to the refinement of the pore network, which contributes to the increased compressive strength. The presence of pores of smaller diameter is important from a durability point of view, considering that the diffusion of aggressive agents into the binders usually takes place through the larger pores.

\subsection{X-ray diffraction}

In samples prepared with Na-based activators, the major crystalline phases previously identified in the unreacted fly ash (Figure 1) are again observed; the crystalline components of the fly ash are un-reactive. In pastes activated with commercial sodium silicate, the main crystalline reaction products identified correspond to a calcium silicate hydrate containing some sodium (N-C-S-H in cement chemistry terminology) $\left(\mathrm{Na}_{2} \mathrm{Ca}_{2} \mathrm{Si}_{2} \mathrm{O}_{7} \cdot \mathrm{H}_{2} \mathrm{O}\right.$; PDF\# 00-022-0891), analcime ( $\left.\mathrm{NaAlSi}_{2} \mathrm{O}_{6} \cdot \mathrm{H}_{2} \mathrm{O}\right)$; PDF\# 00-0020417), gismondine ((Ca,Na $) \mathrm{Al}_{2} \mathrm{Si}_{2} \mathrm{O}_{8} \cdot 4 \mathrm{H}_{2} \mathrm{O} ; \quad$ PDF\# 00-021-0840), Na-P1 zeolite $\left(\mathrm{Na}_{2} \mathrm{Al}_{2} \mathrm{Si}_{2} \mathrm{O}_{8} \cdot x \mathrm{H}_{2} \mathrm{O}\right.$; PDF\# 00-0025-0777) which is also a gismondine type structure, along with the zeolites gonnardite $\left((\mathrm{Na}, \mathrm{Ca})_{2}(\mathrm{Si}, \mathrm{Al})_{5} \mathrm{O}_{10} \cdot 2 \mathrm{H}_{2} \mathrm{O}\right.$; PDF\# 00-042-1381) and mesolite $\left(\mathrm{Na}_{2} \mathrm{Ca}_{2} \mathrm{Al}_{5} \mathrm{Si}_{9} \mathrm{O}_{30} \cdot 8 \mathrm{H}_{2} \mathrm{O}\right.$; PDF\# 00-024-1064), which both present the natrolite type structure. When activating with L300-Na, the Na-P1, analcime and N-C-S-H are not identified; however, a new zeolite structure corresponding to faujasite $\left(\mathrm{Na}_{2} \mathrm{Al}_{2} \mathrm{Si}_{3.3} \mathrm{O}_{10.6} \cdot 7 \mathrm{H}_{2} \mathrm{O}\right)$ (PDF\# 00-012-0228) is detected. These zeolites have been also formed in other fly ash geopolymer systems [41, 42] and through the hydrothermal production of zeolites using a similar fly ash precursor [43, 44].

Figure 5. $\mathrm{Cu}-\mathrm{K}_{\alpha}$ diffractograms of the fly ash activated with Na-based activators. Peaks present in both diffractograms are labeled in only one diffractogram for visual clarity.

The crystallization of zeolites from amorphous aluminosilicates is determined by the dissolution rate of the precursor, which is controlled by at least two processes: (1) the breakage of surface bonds due to the action of solvent and formation of soluble species that leave the surface of the dissolving solid (directly proportional to the external surface area), and (2) the reaction of the soluble species from the liquid phase on/with the surface of the dissolving solid (depending only indirectly on the concentration of $\mathrm{NaOH}$ via the change of the concentrations of reactive silicate and aluminate species in the liquid phase) 
$[34,45]$. Considering that all of the samples have been prepared with the same fly ash precursor, it is likely that the structural differences are associated with variations in the alkalinity provided by the different silicate activators.

In the hydrothermal preparation of pure analcime from pure silica and alumina sources at intermediate alkalinity conditions, the Na-P1 zeolite has been identified in the early stages of reaction, and it then exhibits a gradual dissolution while the crystallization of analcime is taking place; however, increasing the alkalinity in the system favors the formation of faujasite instead of Na-P1 or analcime [46]. Using the commercial silicates here, the coexistence of analcime and Na-P1 zeolites is achieved, along with the formation of a wide range of zeolites. This indicates that the activation conditions promoted by this activator are favoring the nucleation and growth of stable crystalline zeolites. Conversely, using the $\mathrm{NaOH} /$ nanosilica derived activator leads to a lower availability of $\mathrm{SiO}_{2}$ species in the systems, which is likely to maintain a higher alkalinity compared with commercial silicate solutions at the early times of reaction, consequently promoting the formation of faujasite.

Hajimohammadi et al. [47] studied geopolymer formation from systems with separate Si and $\mathrm{Al}$ sources, and observed that analcime formation occurred in systems with low $\mathrm{Si}$ availability, while faujasite development was promoted at intermediate or high rates of high Si availability. This differs from the trends observed here, where reversed results are obtained, indicating that the mechanisms of gel and zeolite nucleation and growth in binders where $\mathrm{Si}$ and $\mathrm{Al}$ sources are separated differ from those where $\mathrm{Si}$ and $\mathrm{Al}$ are provided in parallel by an aluminosilicate precursor (e.g. fly ash) along with an external source of $\mathrm{Si}$ (activator). Considering that analcime is a relatively high-silica zeolite and its formation is likely to occur in areas enriched in $\mathrm{Si}$, it seems that the additional Si species contributed by a highly dissolved activator can favor the formation of this phase when using the commercial sodium silicate.

The use of commercial potassium silicate (S-K) (Figure 6) as activator also promotes the formation of crystalline reaction products, such as lithosite $\left(\mathrm{K}_{3} \mathrm{HAl}_{2} \mathrm{Si}_{4} \mathrm{O}_{13}\right.$; $\mathrm{PDF} \#$ 00-0370457), K-cymrite (KAlSi ${ }_{3} \mathrm{O}_{8} \cdot \mathrm{H}_{2} \mathrm{O}$; PDF\# 00-016-0385) and aluminosilicate zeolites with a chabazite-K type structure $\left(\mathrm{K}_{10.9} \mathrm{Al}_{11.1} \mathrm{O}_{72} \mathrm{Si}_{24.9} \cdot 25 \mathrm{H}_{2} \mathrm{O}\right.$; PDF\# 00-037-0792). K-cymrite is also identified in binders prepared with the L300-K activator, along with hydrodelhayelite 
$\left(\mathrm{KCa}_{2}\left(\mathrm{Si}_{7} \mathrm{Al}\right) \mathrm{O}_{17}(\mathrm{OH})_{2} \cdot 6 \mathrm{H} 2 \mathrm{O} ; \quad\right.$ PDF\# 00-041-0611), and a chabazite-K zeolite

408 ( $\mathrm{KAlSiO}_{4} \cdot x \mathrm{H}_{2} \mathrm{O}$; PDF\# 00-053-1777). The formation of zeolite-like products including

409 calcium (in particular hydrodelhayelite; chabazite is also known to show Ca substitution,

410 although this was not explicitly observable here) is likely to be related to the weaker

411 zeolite structure forming tendencies of potassium here compared to sodium in Figure 5;

412 pure sodium zeolites form reasonably readily, while pure potassium zeolites are less

413 common, which leads to the formation of mixed-cation species as identified here.

Figure 6. $\mathrm{Cu}-\mathrm{K}_{\alpha}$ diffractograms of the fly ash activated with K-based activators. Peaks present in both diffractograms are labeled in only one diffractogram for visual clarity.

\subsection{Thermogravimetry}

The thermograms of the binders (Figure 7) after 28 days of curing exhibit an onset of weight loss at temperatures lower than $300^{\circ} \mathrm{C}$, which is associated with the physically bound and zeolitic water present in the reaction products (dominated by an aluminosilicate type-gel) which can be easily removed from the sodium/potassium silicate gel surface at these temperatures [48-50]. Loss of weight at temperatures higher than $300^{\circ} \mathrm{C}$ is consistent with dehydroxylation by condensation of the bound silanol groups, which is completed at $500^{\circ} \mathrm{C}$ [48].

Figure 7. Thermograms of silicate-activated fly-ash binders at 28 days of curing

Differences in the total weight loss are identified between samples with nanosilica-based activators and commercial silicate activators. This is more marked when comparing samples with different alkali cations, where geopolymers activated by Na salts presented a total weight loss of $\sim 13 \%$ while K-geopolymers presented $\sim 11 \%$ weight loss. This is consistent with the structural differences in the binders as identified by MIP and XRD as discussed above. The total loss of weight in K-activated geopolymer paste is $18 \%$ lower than in the Na-activated specimens, which is consistent with the difference in water content between the samples. However, some of the additional weight loss reported for Na-activated binders may also be attributed to a larger content of gel reaction products having been formed at the time of curing at which these samples were assessed, compared with K-activated samples. This is consistent with the higher compressive strength and 
441 reduced permeability reported for Na-activated samples, independent of the silica source

442 in the activator.

Differential thermogravimetric curves (DTG; Figure 8) show a broad peak from room temperature up to $\sim 300^{\circ} \mathrm{C}$ in all samples. The main peak identified in both S-Na and L300Na geopolymers presents a minimum at $\sim 103^{\circ} \mathrm{C}$, attributed to the freely evaporable water present in large pores in the geopolymer gel. The increased intensity of this peak in samples activated with the commercial silicate solutions indicates a higher extent of aluminosilicate gel formation, coherent with the high compressive strength identified in mortars prepared with this binder. It is important to note that the first minimum related to the loss of weight of evaporable water in these fly ash geopolymers $\left(\sim 103^{\circ} \mathrm{C}\right)$ is at a higher temperature than that which has been reported for metakaolin geopolymers $\left(\sim 58^{\circ} \mathrm{C}\right)$ with comparable formulations [50], indicating that the use of $\mathrm{FA}$ as a precursor for the production of these binders favors the formation of denser geopolymer gels with tightly absorbed water in small pores, or as condensed hydroxyl groups on the surface of the gel $[48,51]$.

Figure 8. Differential thermograms of silicate-activated fly ash

In the samples S-Na and S-K a second peak is also observed at $\sim 141^{\circ} \mathrm{C}$. In MK-based geopolymers and activated MK/GBFS blends the presence of this second peak has been associated with the dehydration of the zeolite-type product (hydroxysodalite in that case) formed along with the geopolymer gel [50]. Oh et al. [52] reported that the geopolymer gel formed through the alkali-activation of fly ash presents a disordered form of the ABC-6 family of zeolitic products, which contains different polytypes such as chabazite, and ranging from amorphous structure to polycrystalline in the case of high alkalinity mixes.

Crystalline chabazite has previously been reported as a zeolitic product in sodium-fly ash geopolymer systems [41]; however, crystalline chabazite structures are observed here exclusively in samples with K-based activators (Figure 6). Weight loss of chabazite-type zeolites has been reported at temperatures of $162^{\circ} \mathrm{C}$ for chabazite-Na ("herschelite"), and $192^{\circ} \mathrm{C}$ for chabazite-K $[53,54]$, which probably indicates that the second peak identified in DTG analysis of these binders (Figure 8) is likely to be related to geopolymer gel with a chabazite-like nanostructure. A higher intensity of this peak is shown for pastes activated 
with commercial silicates, which can be associated with the larger degree of reaction and increased ordering of the gels formed.

A third peak at $\sim 596^{\circ} \mathrm{C}$ is only observed in commercial-silicate activated geopolymers (S$\mathrm{Na}$ and $\mathrm{S}-\mathrm{K}$ ), and is attributed to the complete dehydroxylation of zeolites present in the binder. Conversely, a weaker signal at $509^{\circ} \mathrm{C}$, and a small and poorly defined peak at $490^{\circ} \mathrm{C}$ are identified in L300-Na and L300-K binders respectively. The shifting of the dehydroxylation peak towards lower temperatures is associated with lower alkali and $\mathrm{Al}$ content, because of the greater strength of the bond between the water and the $\mathrm{Na}^{+}$or $\mathrm{K}^{+}$ cations in this case $[55,56]$.

A low intensity peak at $\sim 847^{\circ} \mathrm{C}$ is identified in L300-K, corresponding to decomposition of the carbonates, probably sodium or potassium carbonate (Figure 6). Similar peaks $\left(\sim 780-800^{\circ} \mathrm{C}\right)$ with reduced intensity are also exhibited by S-Na and S-K geopolymers.

\subsection{Scanning electron microscopy (SEM/EDS)}

Fly ash geopolymers activated with commercial sodium silicate (Figure 9) exhibit a heterogeneous gel structure, with embedded particles of varying morphologies (Figure 9A): smooth spherical particles (Figure 9B), agglomerations of rectangular crystalline particles mostly composed of $\mathrm{Al}$ and Si (Figure 9C) surrounded by an Si-rich gel, spherical units formed from the agglomeration of tubular particles enriched in Fe (Figure 9D), and crystalline particles with a dendritic-type structure with a high content of Fe and containing similar proportions of $\mathrm{Al}$ and Si (Figure 9E). Hollow cavities with spherical shape are associated with the partial dissolution of fly ash particles during the geopolymerization reaction, where the un-reacted remnant fly ash particles are not bound to the geopolymer gel, and fall out from their positions in the cavities during sample preparation for microscopic analysis.

In analysis of fly ashes from different sources [57], it has been identified that this material presents a spherical particle shape, mostly consisting of amorphous aluminosilicate, along with iron-rich spheres composed of iron oxide mixed with amorphous aluminosilicate with variations in the contents of $\mathrm{Al}, \mathrm{Si}$ and Fe. Specifically, the ferrospheres in fly ash present 
509 a microstructure that can include smooth, polygonal, dendritic, granular and molten drop

510 characteristics [58], and can often be represented as a nanocomposite with "core-shell"

511 structure, where the core is formed from spinel, hematite and quartz crystals (phases

512 observed by XRD in the fly ash used here), and the shell consists of glasses [59].

514 Considering the chemical compositions of the different phases forming the geopolymer 515 and the microstructural characteristics reported for unreacted fly ash, it is inferred that the 516 smooth spherical particles correspond to undissolved FA, while the agglomerated 517 rectangular particles are identifiable according to their composition as being mullite, and 518 those with dendritic-type structure are likely to be associated with the ferrite spinels 519 previously observed by XRD (Figure 5). This is coherent with the observations made by Lloyd et al. [60] who identified remnant particles of un-reacted fly ash, along with crystalline phases such as mullite, in fly ash-based geopolymers. This is attributed to the differential solubilities of the phases composing the fly ash under the activation conditions used, especially where those presenting high crystallinity are less soluble. In the fly ash assessed, mullite has been identified by XRD, and is likely to be responsible for the particles identified in Figure 9C.

Figure 9. Scanning electron micrographs and corresponding EDS spectra of the binder activated with a commercial sodium silicate (S-Na)

Binders activated with the $\mathrm{NaOH} /$ nanosilica derived activator (Figure 10) present only slight microstructural differences compared with commercial Na-silicate activated pastes. In this case, it is also possible to identify a partially dissolved fly ash particle with a needle-like phase over its surface (Figure 10B), which is rich in $\mathrm{Al}$ and Si. This phase is likely to be associated with mullite crystals, including some $\mathrm{Fe}$ substituting for $\mathrm{Al}$ in the mullite structure [61].

Figure 10. Scanning electron micrographs and corresponding EDS spectra for the binder activated with $\mathrm{NaOH} /$ nanosilica-derived activator (L300-Na)

540 Dendritic type particles assigned to the ferrite spinels forming the unreacted FA are also 541 identified (Figure 10C), which is coherent with XRD (Figure 5). This is consistent with 542 the observations of Lloyd et al. [60] who observed that iron-rich phases in a fly ash 
543 precursor are relatively unreactive. In this binder, a Ca- and Si-rich needle-like 544 morphology is visible inside one of the hollow cavities, presenting some traces of Na and 545 low contents of Al. Taking this into account, this morphology can be associated with some 546 sort of C-S-H phase. It is important to note that XRD results do not reveal the formation of 547 a long range-ordered C-S-H when using this activator; these phases are therefore 548 identifiable as showing at most short-range order.

The geopolymer gel embedding the different particles presents similar chemical composition, independent of the silicate source, using Na-based activators. However, it seems that there is a higher degree of interaction between this gel and the fly ash particles in the binders prepared with the nanosilica-derived activator. This is coherent with the reduced permeability exhibited by this binder (Figure 3), providing further evidence of the effectiveness of using this alternative activator for producing geopolymers.

Binders prepared with a commercial K-silicate activator (Figure 11) also show mullite crystals which were originally embedded within fly ash particles. As the reaction progressed, the glass phase dissolved and exposed the mullite needles. Similarities in the chemical composition of the geopolymer gel formed are again identified between the samples which used the commercial K-silicate activator (Figure 11A) and the $\mathrm{KOH} /$ nanosilicate derived activator (Figure 11B).

Figure 11. Scanning electron micrographs, and corresponding EDS spectra, of the binders activated with (A) commercial potassium silicate solution (S-K) and (B) KOH/nanosilica derived activator

\section{Conclusions}

The production of high mechanical strength and low permeability geopolymers has been achieved using alternative activators based on modified nanosilica. These binders show an extent of reaction which is slightly lower than that of binders produced from the same fly ash using commercial sodium silicate activators, but mechanical strengths are similar. The water demand and porosity of the samples prepared with the nanosilica-based activators are lower than for the case of the commercial silicate activators, which is attributed to the slightly delayed release of silica from the solid nanosilica particles, which remain in 
suspension in the solution during the early ages of reaction and then release silica later in the reaction process. The crystalline zeolite phases formed in the samples differ slightly between the nanosilica-derived and traditional activators, again consistent with the differences in silica release rates from the two activators. Microstructural analysis shows that the geopolymer gel is more tightly bound to the partially reacted fly ash particles in the case of the nanosilica-derived activator, consistent with the reduced porosity of these binders. The use of the nanosilica activator may also bring advantages in terms of the environmental profile of the materials.

\section{Acknowledgements}

This study was sponsored by the Ministerio de Ciencia e Innovación of Spain (Project GEORES MAT2010-19934 and research scholarship BES-2008-002440), European regional development fund (FEDER), and the Universitat Politècnica de València (Spain). The participation of SAB and JLP was funded by the Australian Research Council (ARC), including partial funding through the Particulate Fluids Processing Centre, a Special Research Centre of the ARC. A special acknowledgement is also due to the Centre of Electron Microscopy of the Universitat Politècnica de València and Pedro Garcés from the Universidad de Alicante for support in some experiments.

\section{References}

1. Duxson P., Fernández-Jiménez A., Provis J.L., Lukey G.C., Palomo A., van Deventer J.S.J. Geopolymer technology: the current state of the art. J Mater Sci 2007, 42(9): 2917-2933.

2. Duxson P., Provis J.L., Lukey G.C., van Deventer J.S.J. The role of inorganic polymer technology in the development of green concrete. Cem Concr Res 2007, 37(12): 1590-1597.

3. van Deventer J.S.J., Provis J.L., Duxson P., Brice D.G. Chemical research and climate change as drivers in the commercial adoption of alkali activated materials. Waste Biomass Valor 2010, 1(1):145-155.

4. van Jaarsveld J.G.S., van Deventer J.S.J. Effect of the alkali metal activator on the properties of fly ash-based geopolymers. Ind Eng Chem Res, 1999, 38(10):39323941 , 
5. Phair J.W., van Deventer J.S.J. Effect of silicate activator $\mathrm{pH}$ on the leaching and material characteristics of waste-based inorganic polymers. Miner Eng 2001, 14(3):289-304.

6. Fernández-Jiménez A., Palomo A. Composition and microstructure of alkali activated fly ash binder: Effect of the activator. Cem Concr Res 2005, 35:1984 - 1992

7. Yang K.-H., Song J.-K., Ashour A.F., Lee E.-T. Properties of cementless mortars activated by sodium silicate. Constr Build Mater 2008, 22(9):1981-1989.

8. Yang K.-H., Song J.-K. Workability loss and compressive strength development of cementless mortars activated by combination of sodium silicate and sodium hydroxide. J Mater Civ Eng 2009, 21: 119-127

9. Hajimohammadi A., Provis J.L., van Deventer J.S.J. One-part geopolymer mixes from geothermal silica and sodium aluminate. Ind Eng Chem Res. 2009, 47(23): 93969405.

10. Duxson P., Mallicoat S.W., Lukey G.C., Kriven W.M., van Deventer J.S.J. The effect of alkali and $\mathrm{Si} / \mathrm{Al}$ ratio on the development of mechanical properties of metakaolinbased geopolymers. Colloids Surf A 2007, 292(1): 8-20.

11. Fernández-Jiménez A., Palomo A., Criado M. Alkali activated fly ash binders. A comparative study between sodium and potassium activators. Mater Constr. 2006, 56(281): 51-56.

12. Provis, J.L. Activating solution chemistry for geopolymers. In: Provis J.L., van Deventer, J.S.J. (editors.) Geopolymers: Structures, Processing, Properties and Industrial Applications, Woodhead Publishing, Abingdon UK, 2009, p50-71.

13. McCormick A.V., Bell A.T. The solution chemistry of zeolite precursors. Catal Rev Sci Eng 1989, 31: 97-127.

14. Witherspoon R., Wang H., Aravinthan T., Omar T. Energy and emissions analysis of fly ash based geopolymers. Proceedings of SSEE 2009 International Conference. Melbourne, Australia, 2009.

15. Tempest B., Sanusi O., Gergely J., Ogunro V., Weggel D. Compressive strength and embodied energy optimization of fly ash based geopolymer concrete. Proceedings of the 2009 World of Coal Ash (WOCA) conference. Lexington, KY, USA, 2009.

16. McLellan B.C., Williams R.P., Lay J., van Riessen A., Corder G.D. Costs and carbon emissions for geopolymer pastes in comparison to ordinary Portland cement. J Cleaner Prod 2011, 19: 1080-1090. 
17. Deabriges J. Process for the manufacture of sodium silicate. United States Patent 4,336,235, 1982.

18. Fawer M., Concannon M., Rieber W. Life cycle inventories for the production of sodium silicates. Int J Life Cycle Assess 1999, 4(4): 207-212.

19. Živica V. High effective silica fume alkali activator. Bull Mater Sci 2004, 27(2): 179182.

20. Živica V. Effectiveness of new silica fume alkali activator. Cem Concr Compos 2006. 28(1): 21-25.

21. Rouseková I., Bajza A., Živica V. Silica fume-basic blast furnace slag systems activated by an alkali silica fume activator. Cem Concr Res 1997, 27(12): 1825-182

22. Rodríguez E. Effect of $\mathrm{Si} / \mathrm{Al} / \mathrm{Na} / \mathrm{Ca}$ ratio in geopolymeric materials based on metakaolin. Master Thesis. Universidad del Valle. Cali, Colombia. 2008.

23. Rodríguez E. Effectiveness of alkali-activators based on different sources of silica for the manufacture of fly ash geopolymer systems. Master Thesis. Universidad Politécnica de Valencia, Spain. 2009.

24. Detphan S., Chindaprasirt P. Preparation of fly ash and rice husk ash geopolymer. Int J Miner Metall Mater 2009, 16(6): 720-126.

25. Songpiriyakij S., Kubprasit T., Jaturapitakkul Ch., Chindaprasirt P. Compressive strength and degree of reaction of biomass and fly ash-based geopolymer. Constr Build Mater 2010, 24(3): 236-240.

26. Bernal S.A., Rodríguez E.D., Mejía de Gutiérrez R., Provis J.L., Delvasto S. Activation of metakaolin/slag blends using alkaline solutions based on chemically modified silica fume and rice husk ash. Waste Biomass Valor 2012, 3(1): 99-108.

27. Wongpa J., Kiattikomol K., Jaturapitakkul C., Chindaprasirt P. Compressive strength, modulus of elasticity, and water permeability of inorganic polymer concrete. Mater Des 2010, 31: 4748-4754.

28. Winburn R.S., Lerach S.L., McCarthy G.J., Grier D.G., Cathcart J.D. Quantification of ferrite spinel and hematite in fly ash magnetically enriched fractions. Adv X-Ray Anal 2000, 43: 350-355.

29. Vassileva S.V., Menendez R., Alvarez D., Diaz-Somoano M., Martinez-Tarazona M.R. Phase-mineral and chemical composition of coal fly ashes as a basis for their multicomponent utilization. 1. Characterization of feed coals and fly ashes. Fuel 2003, 82:1793-181 
30. Williams R.P., van Riessen A. Determination of the reactive component of fly ashes for geopolymer production using XRF and XRD. Fuel 2010, 89(12): 3683-3692.

31. Provis J.L., Rose V., Bernal S.A., van Deventer J.S.J. High-resolution nanoprobe Xray fluorescence characterization of heterogeneous calcium and heavy metal distributions in alkali-activated fly ash. Langmuir 2009, 25(19): 11897-11904

32. Bahlmann E.K.F., Harris R.K., Rockliffe J.W., Smith E.G. Silicon-29 NMR selfdiffusion and chemical-exchange studies of concentrated sodium silicate solutions. J Chem Soc, Faraday Trans. 1997, 93: 93-98.

33. Hewlett P.C. Lea's Chemistry of Cement and Concrete, $4^{\text {th }}$ Ed. Elsevier, Oxford, UK, 1998

34. Duxson P., Provis J.L. Designing precursors for geopolymer cements. J Am Ceram Soc 2008. 91(12): 3864-3869.

35. Xu, H., van Deventer, J.S.J., Lukey, G.C. Effect of alkali metals on the preferential geopolymerization of stilbite/kaolinite mixtures. Ind Eng Chem Res 2001, 40(17): 3749-3756.

36. Duxson P., Lukey G.C., Separovic F., van Deventer J.S.J. Effect of alkali cations on aluminium incorporation in geopolymeric gels. Ind Eng Chem Res 2005, 44(4): 832839.

37. Duxson P., Provis J.L., Lukey G.C., van Deventer J.S.J., Separovic F., Gan Z.H. ${ }^{39} \mathrm{~K}$ NMR of free potassium in geopolymers. Ind Eng Chem Res 2006. 45(26): 9208-9210.

38. Diamond S. Mercury porosimetry. An inappropriate method for the measurement of pore size distribution in cement-based materials. Cem Concr Res 2000, 30: 15171525.

39. Washburn E.W. Note on method of determining the distribution of pore sizes in porous materials. Proc Nat Acad Sci U.S.A. 1921, 7(4): 115-116.

40. Kovalchuk G., Fernández-Jiménez A., Palomo A. Alkali-activated fly ash: Effect of thermal curing conditions on mechanical and microstructural development - Part II. Fuel 2007, 86: 315-322

41. Criado M., Fernández-Jiménez A., de la Torre A.G., Aranda M.A.G., Palomo A. An XRD study of the effect of the $\mathrm{SiO}_{2} / \mathrm{Na}_{2} \mathrm{O}$ ratio on the alkali activation of fly ash. Cem Concr Res 2007, 37: 671-679

42. Lloyd R.R. Accelerated ageing of geopolymers. In: Provis J.L, van Deventer, J.S.J. (Eds.) Geopolymers: Structures, Processing, Properties and Industrial Applications, Woodhead Publishing, Abingdon UK. 2009, p. 139-166. 
43. Querol X., Alastuey A., Fernández-Turiel J.L., López-Soler A. Synthesis of zeolites by alkaline activation of ferro-aluminous fly ash. Fuel 1995, 74(8): 1226-1231.

44. Querol X., Plana F., Alastuey A., López-Soler A. Synthesis of Na-zeolites from fly ash. Fuel 1997, 76(8): 793-799.

45. Antonić T., Čižmek A., Subotić B. Dissolution of amorphous aluminosilicate zeolite precursors in alkaline solutions: Part 2.- Mechanism of the dissolution. J Chem Soc Faraday Trans 1994, 90(13): 1973-1977.

46. Kohoutková M., Kloužkova A., Maixner J., Mrázová M. Preparation and characterization of analcime powders by X-ray and SEM analysis. Ceram-Silik 2007, 51(1): 9-14.

47. Hajimohammadi A., Provis J.L., van Deventer J.S.J. The effect of silica availability on the mechanism of geopolymerisation. Cem Concr Res 2011, 41(3): 210-216.

48. Duxson P., Lukey G.C., van Deventer J.S.J. The thermal evolution of metakaolin geopolymers: Part 1 - Physical evolution. J Non-Cryst Solids 2006, 352:5541-5555.

49. Duxson P., Lukey G.C., van Deventer J.S.J. The thermal evolution of metakaolin geopolymers: Part 2 - Phase stability and structural development. J Non-Cryst Solids 2007, 353:2186-2200.

50. Bernal S.A., Rodríguez E.D., Mejía de Gutiérrez R., Gordillo M., Provis J.L. Mechanical and thermal characterization of geopolymers based on silicate-activated metakaolin/slag blends J Mater Sci. 2011, 46(16): 5477-5486.

51. Duxson P., Lukey G.C., van Deventer J.S.J. Physical evolution of Na-geopolymer derived from metakaolin up to $1000^{\circ}$ C. J Mater Sci 2007, 42:3044-3054.

52. Oh J.E., Monteiro P.J.M., Jun S.S., Choi S., Clark S.M. The evolution of strength and crystalline phases for alkali-activated ground blast furnace slag and fly ash-based geopolymers. Cem Concr Res 2010, 40: 189-196.

53. Sticher H. Thermal analysis of synthetic (near-chabazite) zeolites with different $\mathrm{Si} / \mathrm{Al}$ ratios. Thermochim Acta 1974, 10: 305-311.

54. Stakebake J.L. Characterization of natural chabazite and 5A synthetic zeolites. Part 1. Thermal outgassing properties. J Colloid Interf Sci 1984, 99(1): 41-49.

55. Mishin I.V., Piloyan G.A., Klyachko-Gurvich A.L., Rubinshtein A.M. Study of decationized and dealuminized mordenites by the differential-thermal analysis method and measurement of water vapour absorption. Russ Chem Bull 1973, 22(6): 12981300. 
56. Chandwadkar A.J., Kulkarni S.B. Thermal behaviour of modified faujasites. J Thermal Anal 1980, 19: 313-320.

57. Kutchko B.G., Kim A.G. Fly ash characterization by SEM-EDS. Fuel 2006. 85:25372544.

58. Xue Q.-F., Lu S.-G. Microstructure of ferrospheres in fly ashes: SEM, EDX and ESEM analysis. J Zhejiang Univ Sci A 2008, 9(11): 1595-1600.

59. Zyryanov V.V., Petrov S.A., Matvienko A.A. Characterization of spinel and magnetospheres of coal fly ashes collected in power plants in the former USSR. Fuel 2011, 90: 486-492.

60. Lloyd R.R., Provis J.L., van Deventer J.S.J. Microscopy and microanalysis of inorganic polymer cements. 1: Remnant fly ash particles. J Mater Sci 2009, 44: 608619.

61. Gomes S., François M. Characterization of mullite in silicoaluminous fly ash by XRD, TEM and ${ }^{29}$ Si MAS NMR. Cem Concr Res 2000, 30:175-181. 
Table 1. Chemical composition of the fly ash from X-ray fluorescence analysis. LOI is

761 loss on ignition at $950{ }^{\circ} \mathrm{C}$

\begin{tabular}{cccccccccc}
\hline $\begin{array}{c}\text { Component } \\
\text { (weight \% as oxide) }\end{array}$ & $\mathrm{SiO}_{2}$ & $\mathrm{Al}_{2} \mathrm{O}_{3}$ & $\mathrm{Fe}_{2} \mathrm{O}_{3}$ & $\mathrm{CaO}$ & $\mathrm{MgO}$ & $\mathrm{SO}_{3}$ & $\mathrm{Na}_{2} \mathrm{O}$ & $\mathrm{K}_{2} \mathrm{O}$ & $\mathrm{LOI}$ \\
\hline Flyash & 39.00 & 28.01 & 15.43 & 10.27 & 1.50 & 2.00 & 0.71 & 1.38 & 1.69 \\
\hline
\end{tabular}

762

763 
Table 2. Chemical composition of reference silicate activators and nanosilica used to prepare nanosilica/MOH activators; data provided by the suppliers

\begin{tabular}{cccccc}
\hline $\begin{array}{c}\text { Component } \\
\text { (weight \% as oxide) }\end{array}$ & $\mathrm{SiO}_{2}$ & $\mathrm{Na}_{2} \mathrm{O}$ & $\mathrm{K}_{2} \mathrm{O}$ & $\mathrm{H}_{2} \mathrm{O}$ & $\begin{array}{c}\text { Solution modulus } \\
(\mathbf{M s})\left(\mathrm{SiO}_{2} / \mathbf{M}_{2} \mathrm{O}\right)\end{array}$ \\
\hline SS & 28.7 & 8.7 & - & 62.4 & 3.30 \\
$\mathrm{SK}$ & 23.0 & - & 10.5 & 66.5 & 2.19 \\
L300 & 35.7 & - & - & 64.3 & - \\
\hline
\end{tabular}

766

767 
Table 3. Mix description of silicate-activated fly ash binders

\begin{tabular}{ccccc}
\hline \multirow{2}{*}{ Properties } & \multicolumn{4}{c}{ Mixture ID } \\
\cline { 2 - 5 } & $\mathbf{S}-\mathbf{N a}$ & $\mathbf{S}-\boldsymbol{K}$ & $\mathbf{L 3 0 0 - N a}$ & $\mathbf{L 3 0 0 - K}$ \\
\hline alkali cation & $\mathrm{Na}^{+}$ & $\mathrm{K}^{+}$ & $\mathrm{Na}^{+}$ & $\mathrm{K}^{+}$ \\
silicate source & $\mathrm{SS}$ & $\mathrm{SK}$ & $\mathrm{L} 300$ & $\mathrm{~L} 300$ \\
water/binder ratio & 0.27 & 0.21 & 0.20 & 0.13 \\
\hline
\end{tabular}

769

770 


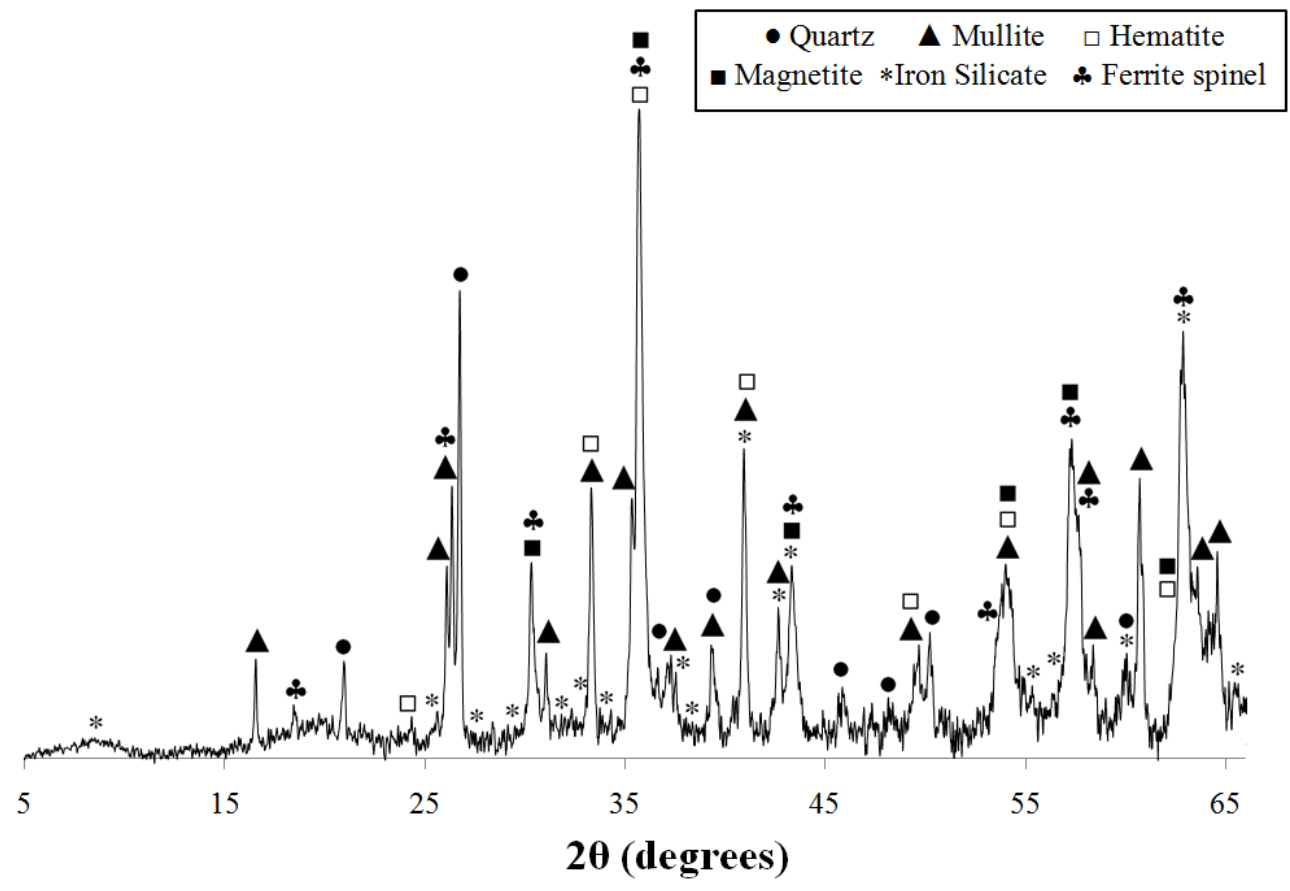

Figure 1. $\mathrm{Cu}-\mathrm{K}_{\alpha}$ diffractogram of the fly ash after mechanical treatment 


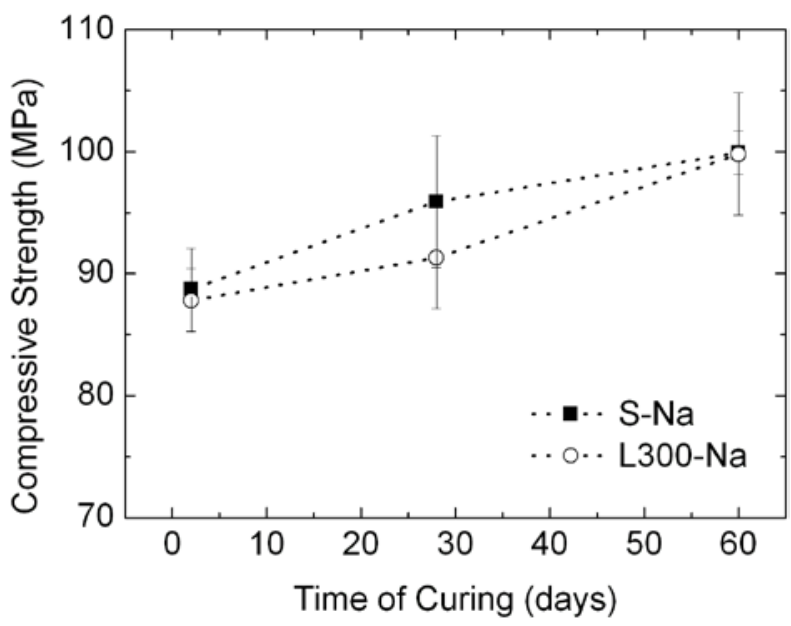

775

776

777

778

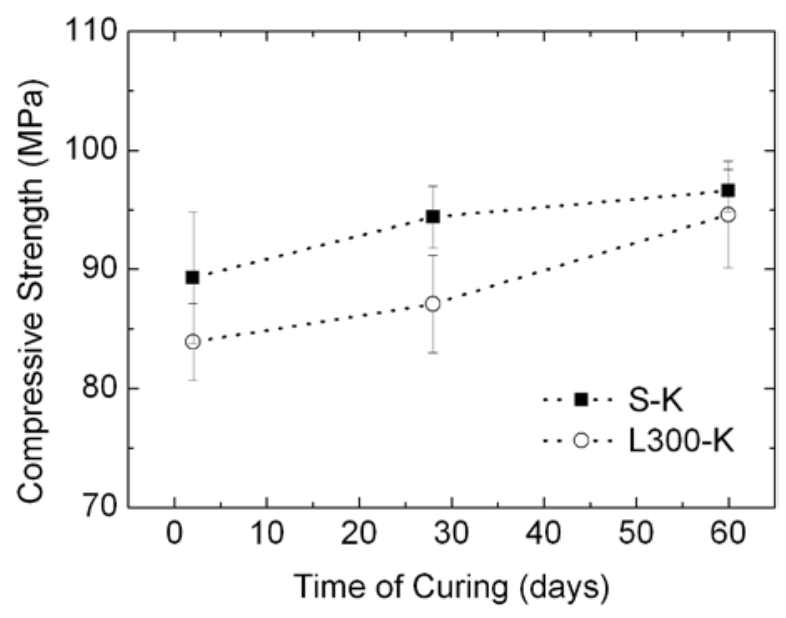

Figure 2. Compressive strength of alkali-activated fly ash mortars, as a function of the nature of the activator. Error bars indicate one standard deviation either side of the mean. 

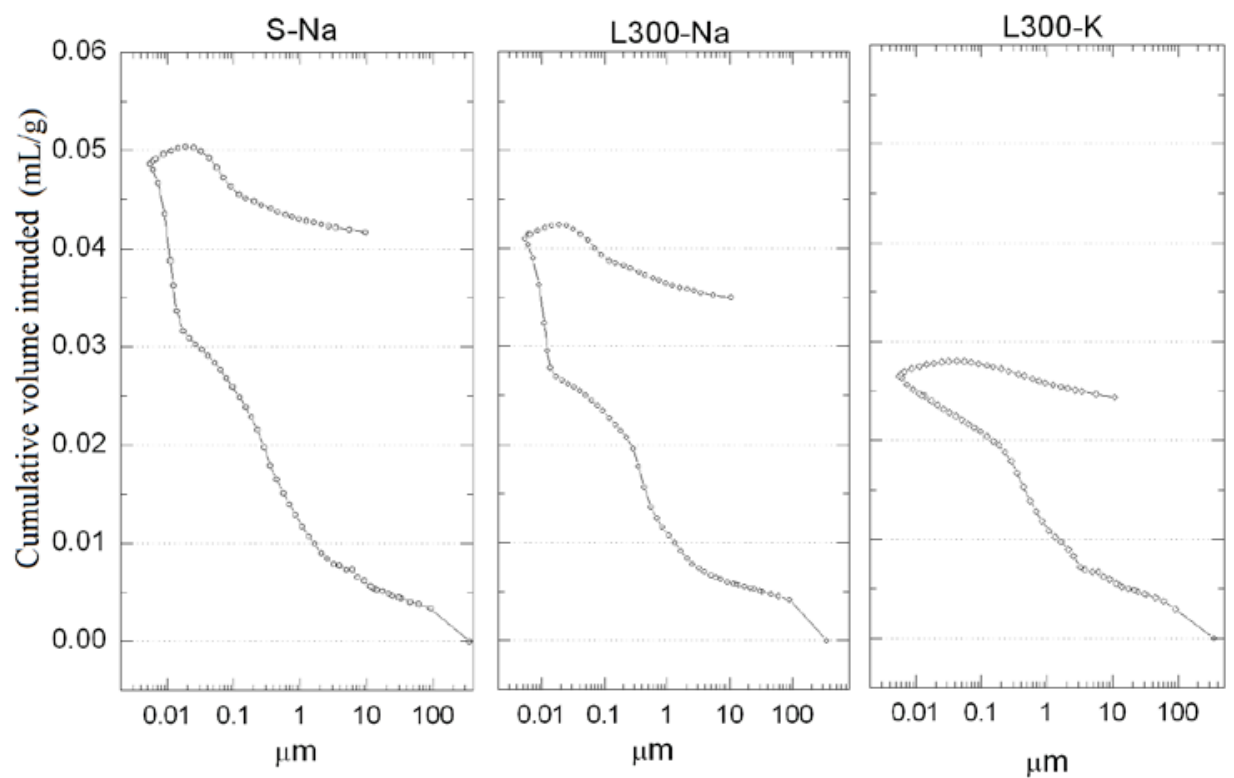

Pore diameter

Figure 3. Cumulative volume of mercury intruded as a function of pore diameter for S- 


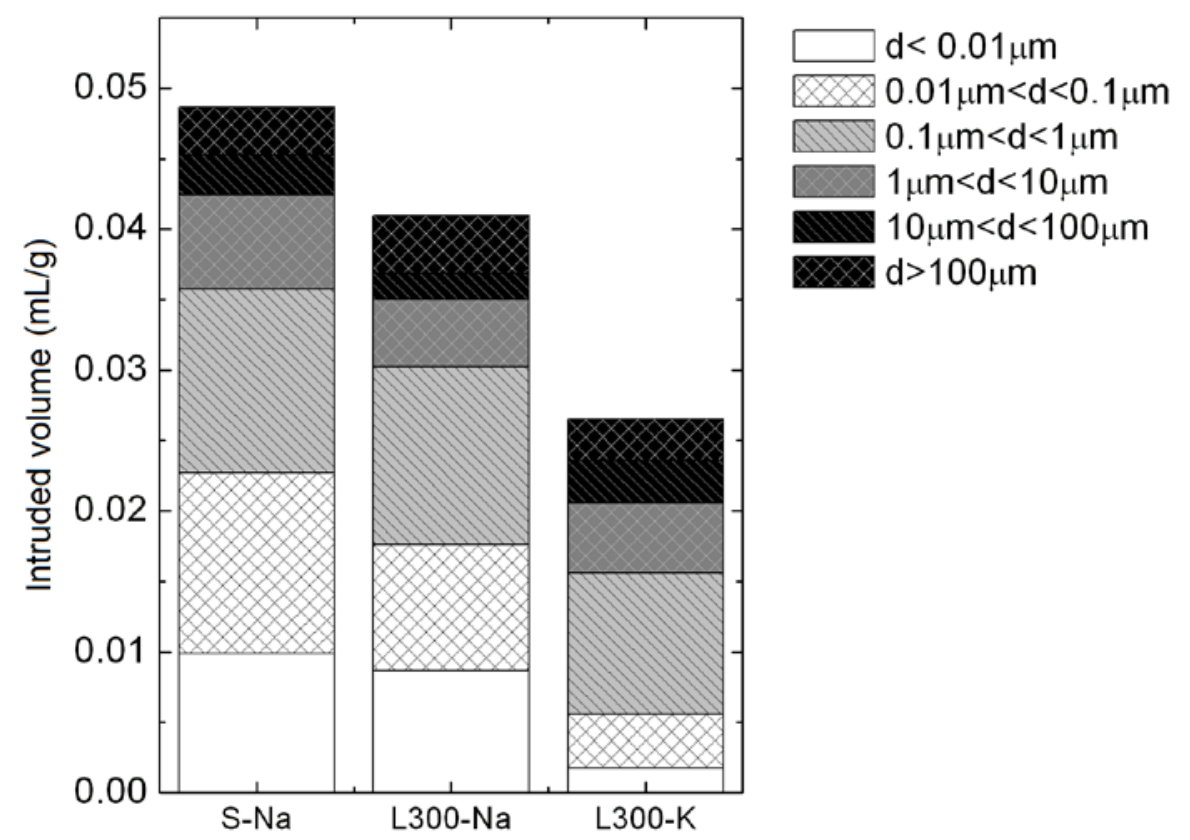

784

Figure 4. Pore size distributions obtained from mercury intrusion data for silicate785 activated fly ash mortars with 28 days of curing 


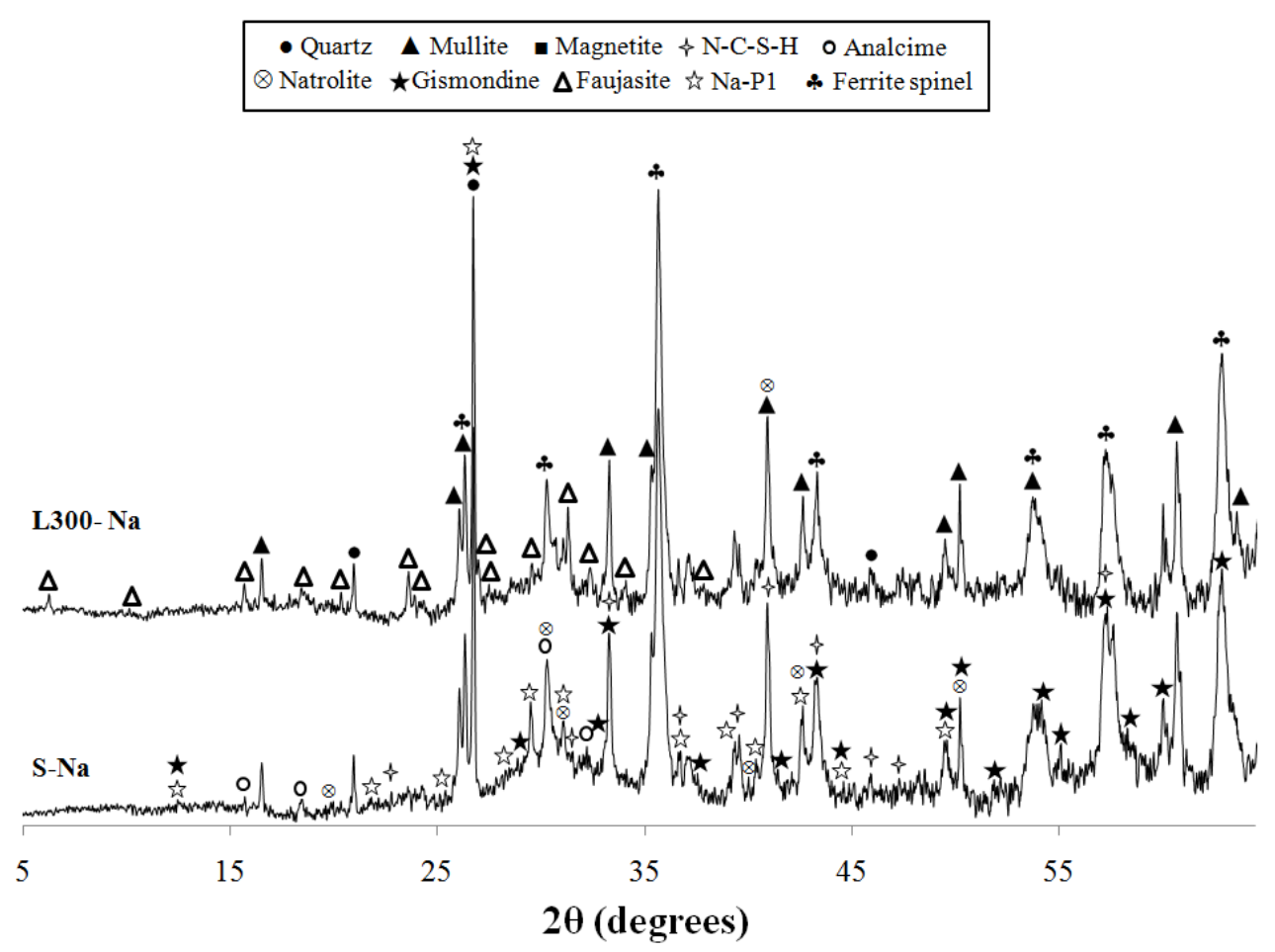

Figure 5. Cu- $\mathrm{K}_{\alpha}$ diffractograms of the fly ash activated with Na-based activators. Peaks present in both diffractograms are labeled in only one diffractogram for visual clarity. 


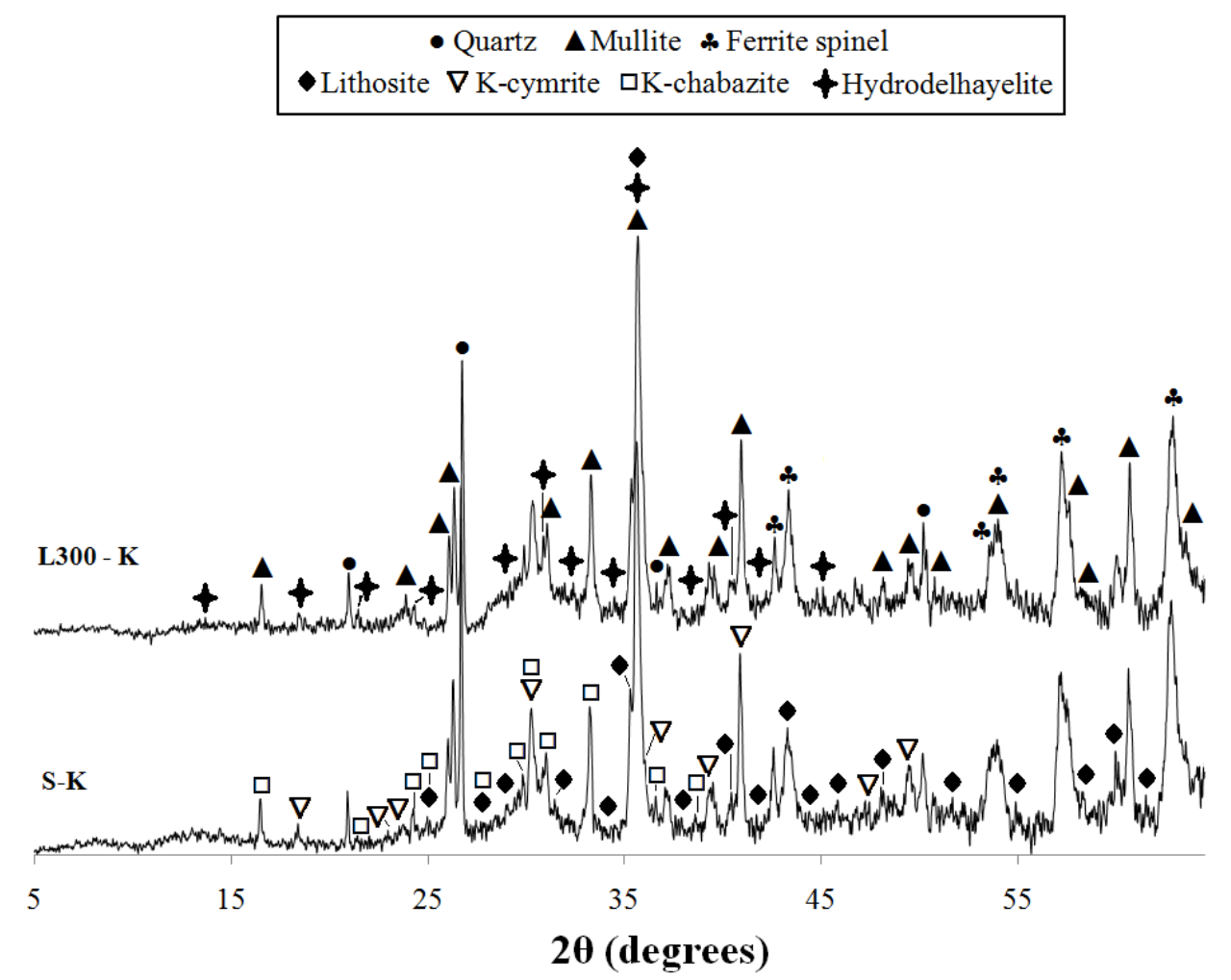

Figure 6. $\mathrm{Cu}-\mathrm{K}_{\alpha}$ diffractograms of the fly ash activated with K-based activators. Peaks

794 present in both diffractograms are labeled in only one diffractogram for visual clarity. 


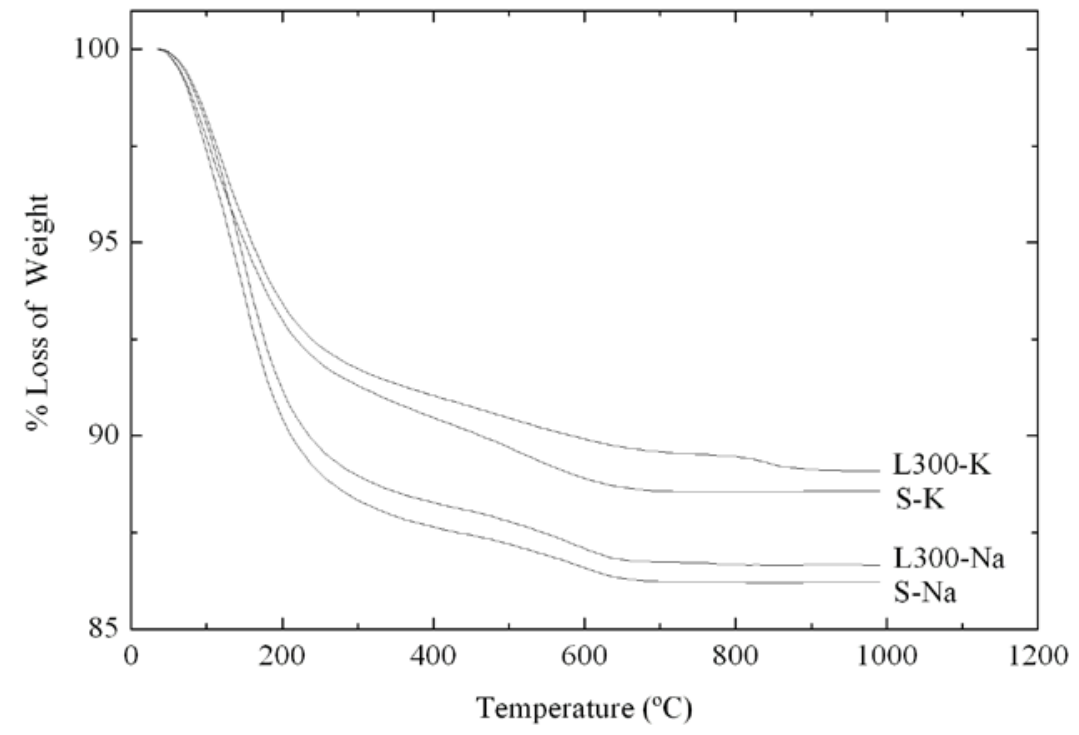

797

Figure 7. Thermograms of silicate-activated fly-ash binders at 28 days of curing 

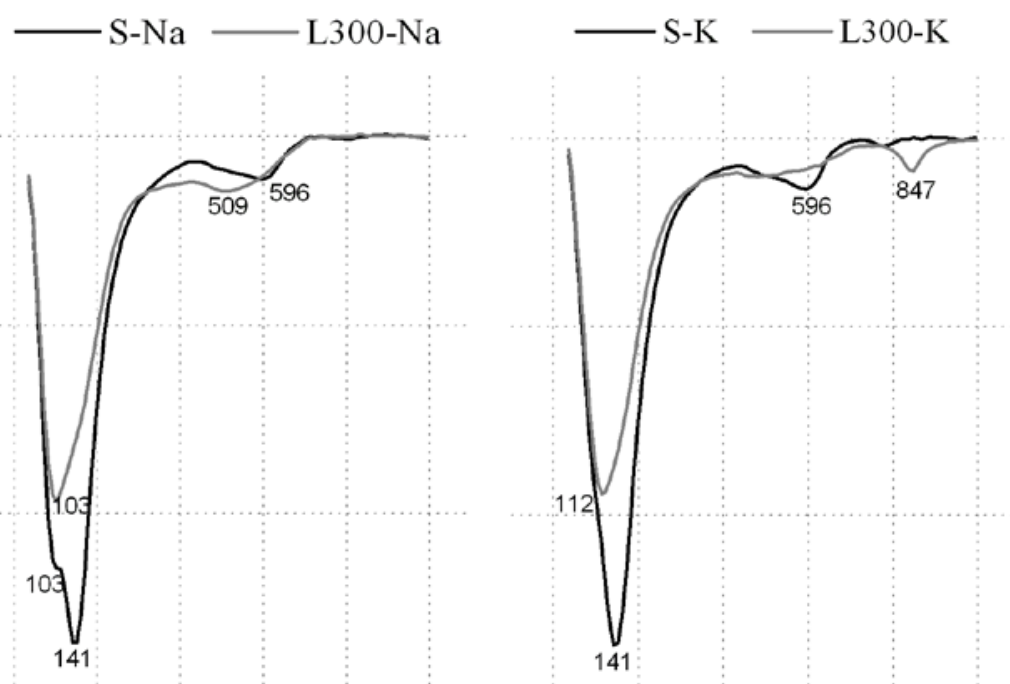

$0 \quad 200 \quad 400 \quad 600 \quad 8001000$

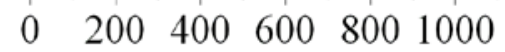

Figure 8. Differential thermograms of silicate-activated fly ash

801 

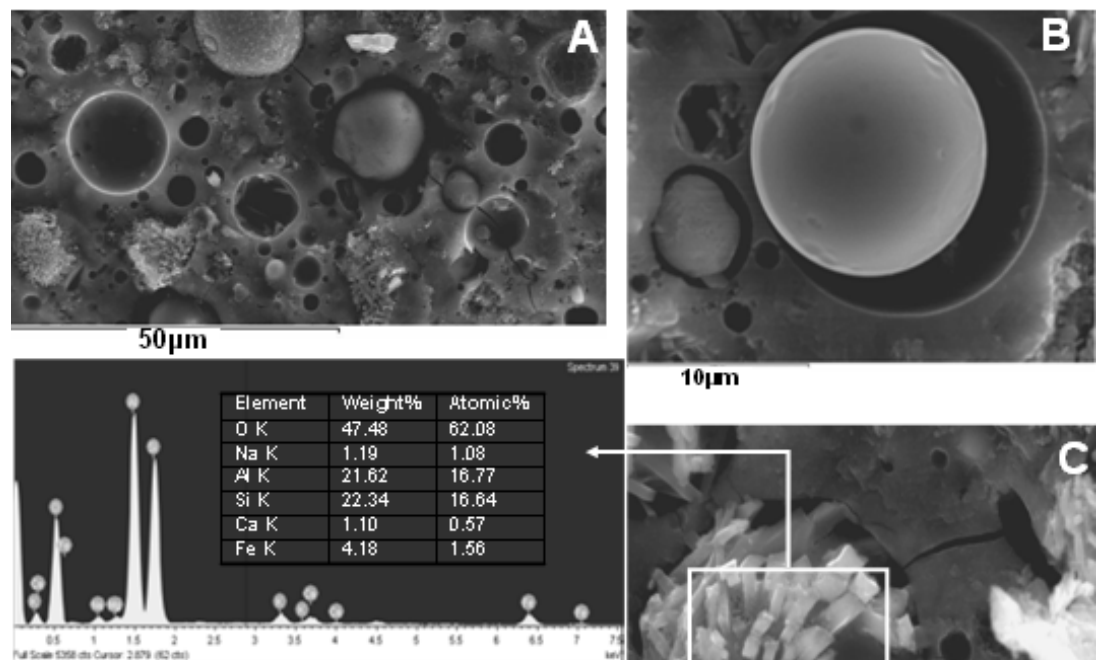

$101 \mathrm{~m}$
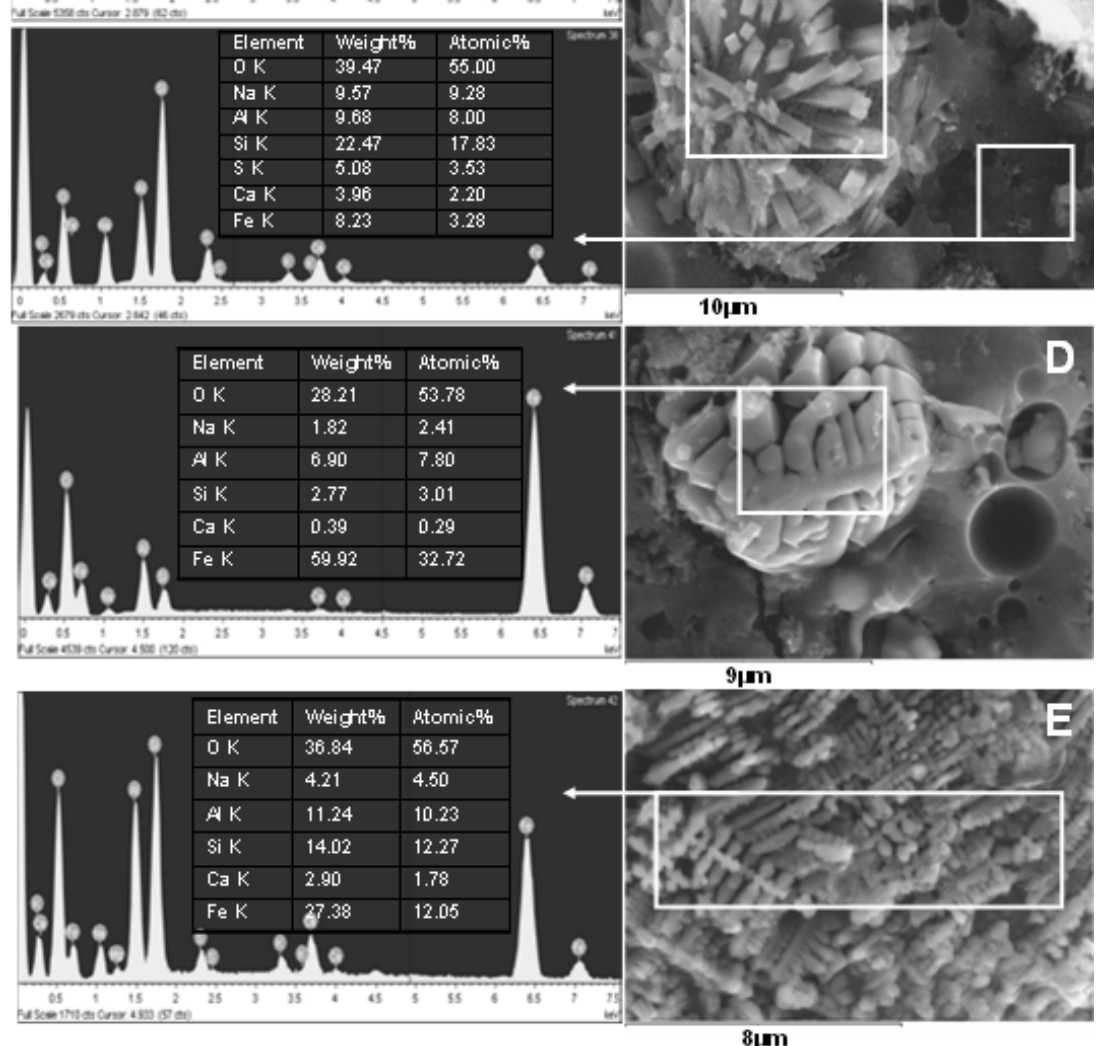

802

803

804

805
Figure 9. Scanning electron micrographs and corresponding EDS spectra of the binder activated with a commercial sodium silicate (S-Na) 

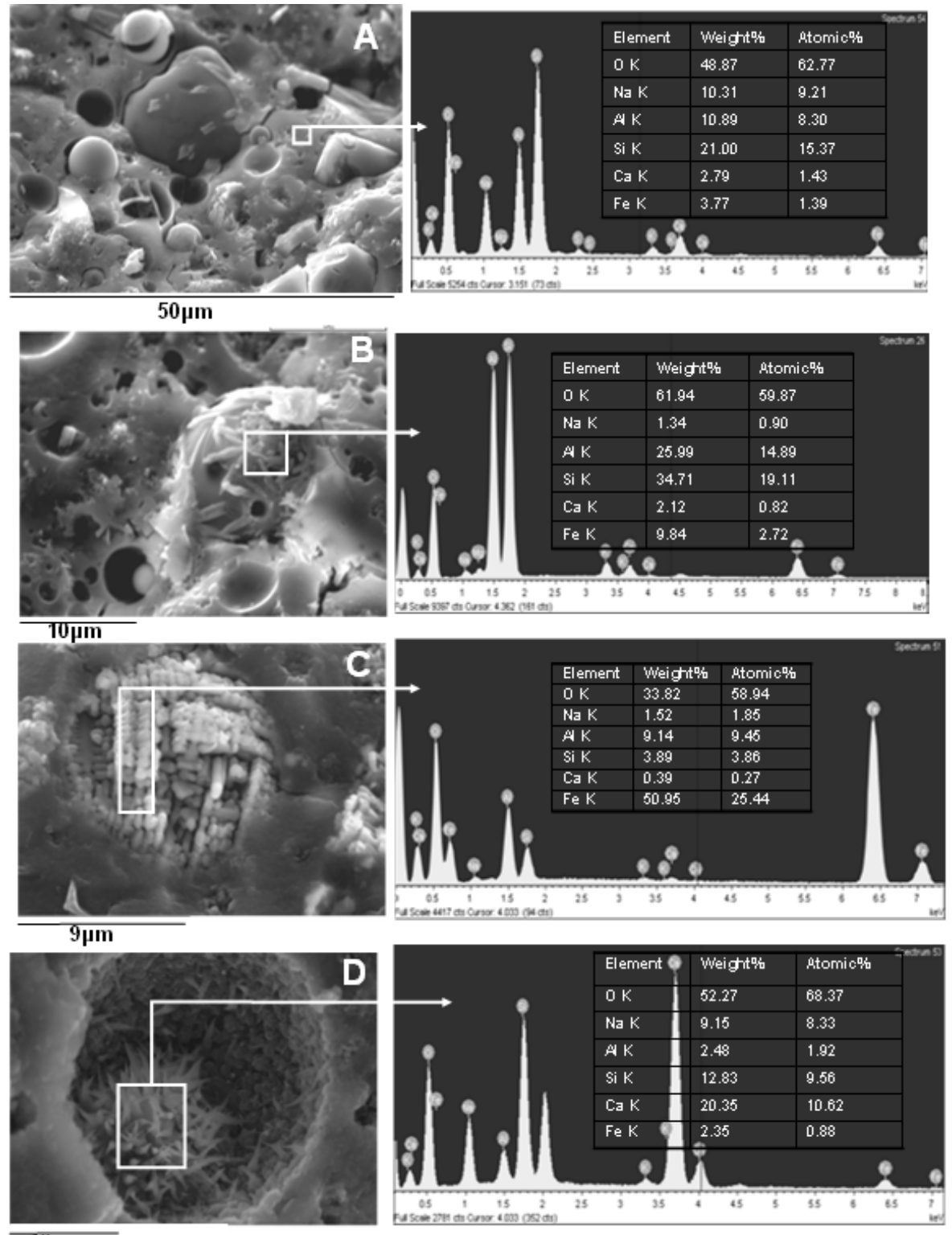

806 $10 \mu \mathrm{m}$

Figure 10. Scanning electron micrographs and corresponding EDS spectra for the binder 808 activated with $\mathrm{NaOH} /$ nanosilica-derived activator (L300-Na) 

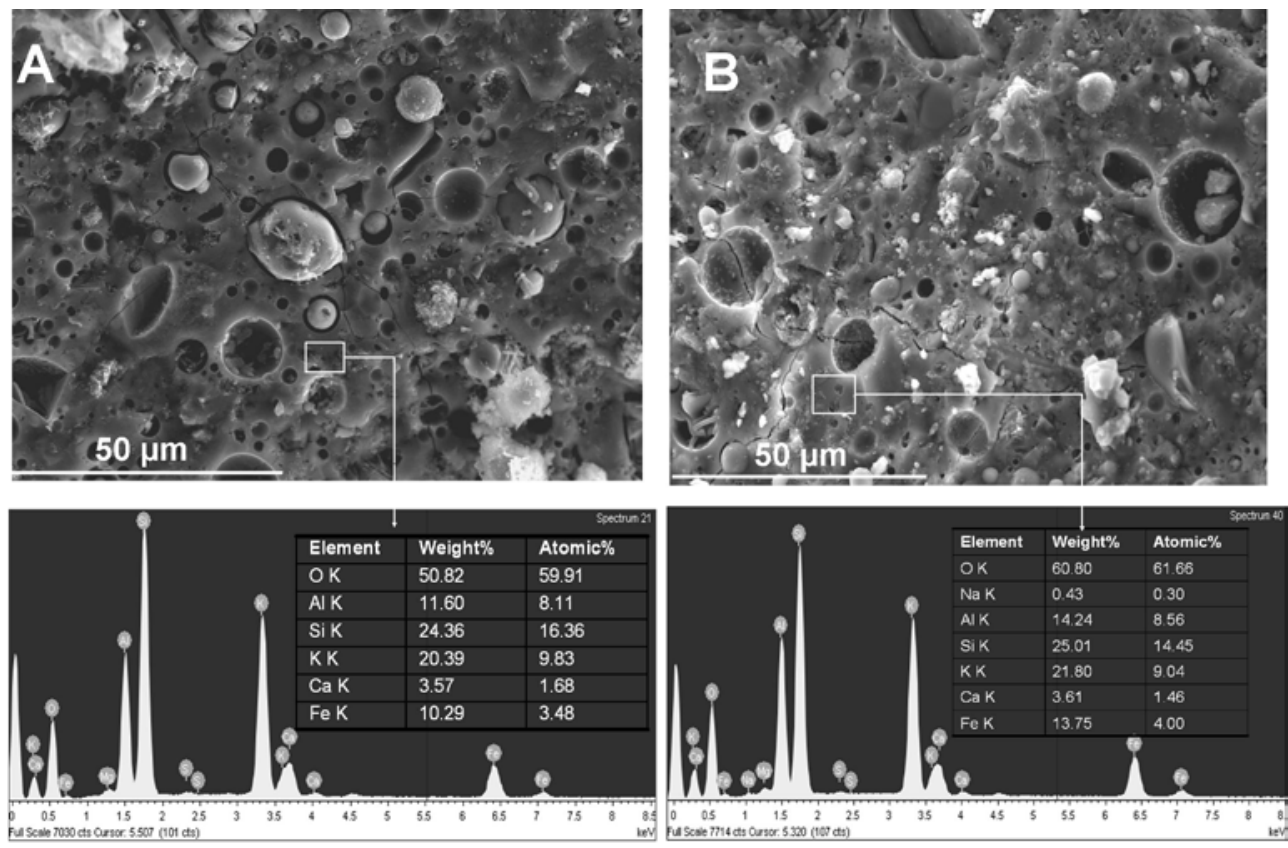

810

Figure 11. Scanning electron micrographs, and corresponding EDS spectra, of the binders activated with (A) commercial potassium silicate solution (S-K) and (B) KOH/nanosilica 